\title{
Perceptions and Uptake of Open Source in Swedish Organisations
}

\author{
Björn Lundell, Brian Lings, and Edvin Lindqvist \\ University of Skövde, P.O. Box 408, SE-541 28 Skövde, Sweden \\ \{bjorn.lundell | brian.lings | edvin.lindqvist\}@his.se, \\ WWW home page: http://Www.his.se/lunb
}

\begin{abstract}
There are many different ways in which Open Source ideas can be adopted by business, and influence the way in which companies do business. A number of different surveys have been conducted in different countries with the purpose of understanding the state of practice with respect to Open Source in companies. A number of different business models have been observed, ranging from the use of Open Source infrastructure products to basing a company's entire business model on Open Source. In this paper we report on a study of the perceptions of Open Source and the uptake of open source products and development models in Swedish companies. We investigate this from the standpoint of stakeholders in those companies which have an expressed interest in Open Source, allowing a more in-depth analysis of the extent to which Open Source has influenced business thinking. From our analysis we find that uptake is much higher than reported in earlier studies, but is still concentrated in SMEs, consistent with the findings of previous studies. There is increased evidence of interest beyond the simple use of OS components at the (LAMP) infrastructure level. In particular, a significant proportion of the companies are in a symbiotic relationship with the OS community, supporting both through participation in existing projects and the release of new software under OS licences.
\end{abstract}

Keywords: Open Source in Swedish Companies, Qualitative Survey, Open Source Adoption, Perceptions of Open Source.

\section{Introduction}

Open Source (OS) is an issue of increasing significance for organisations today [1], all the more so given current perceptions that it can offer effective business solutions and new business opportunities. Most companies will be aware at least of elements of the LAMP suite [2], even if they are not yet using them. However, as well as involvement in conventional OS component adoption many companies are getting involved in open source software (OSS) development projects, considering that in itself this can bring competitive advantages. There is in particular a strong European interest in Open Source (or Libre), with an ITEA report [3] suggesting that $70 \%$ of

Please use the following format when citing this chapter:

Lundell, B., Lings, B., and Lindqvist, E., 2006, in IFIP International Federation for Information Processing, Volume 203, Open Source Systems, eds. Damiani, E., Fitzgerald, B., Scacchi, W., Scotto, M., Succi, G., (Boston: Springer), pp. 155-163 
OSS developers live within the EU, and several EU funded projects investigating the phenomenon (e.g. FLOSS, COSPA, Calibre, OSIRIS, COSI).

A number of surveys have considered the OS phenomenon from a variety of perspectives [4-8]. There have been few previous studies of the OSS phenomenon in a Swedish context. One notable recent exception is the study by Dahlander and Magnusson [9]. Case studies were undertaken in three Swedish companies, investigating the relationship between companies and the OS community. This led to a characterisation of three types of relationship: parasitic (in which the commercial interest is indifferent to its effect on OSS) - of great concern to the OSS community ${ }^{1}$ as over-exploitation can threaten the "OSS ecosystem"; symbiotic (in which each gains advantage); and commensalistic (referring to a commercial interest not harming the OSS project). Apart from benefiting by improving an OSS product on which a company relies, a symbiotic relationship may result from less obvious benefits. For example, Lussier [10] details an instance of process enhancement in a company brought about through the experience of its developers in an OSS development project. Within our study we found evidence of symbiotic and commensalistic relationships.

The FLOSS project [11] included a telephone survey of companies and public organisations in Germany, Sweden and the UK with at least 100 employees. Those identified as using OSS (in total 395 for the three countries) were further surveyed, using a quantitative questionnaire. The lowest represented sector in this survey was found to be large Swedish companies (at least 500 employees).

The goal of the research reported here was to investigate the state of practice with respect to Open Source in Swedish companies across the SME and large company sectors which have adopted OSS. In particular, it was designed to get an insight into the views of key individuals influencing OS practice and policy within the companies.

\section{Research Method}

In this paper, we report on a telephone survey of companies selected via purposeful sampling. The survey is a qualitative study of Swedish practitioners within companies known to be active users of OSS. Company size was not a selection factor. The qualitative techniques used are designed to lead to richer information on the phenomenon studied, but do not allow any claim that the results are representative of organisations generally. However, the FLOSS project suggests that Swedish companies lag somewhat behind those in the UK and Germany in their uptake of OS, so the level of OS perceptions reported here may somewhat under-represent those held more generally within the EU.

Sampling was conducted starting from an initial shortlist of practitioners known by the researchers to be interested in OS. Prior knowledge of OS-related activities

${ }^{1}$ A recurring concern raised by practitioners during the EU FP6 Calibre series of industrial conferences/workshops. 
informed further searches in IT magazines and on the WWW for company involvement in OS, and for practitioner involvement in OS-related seminars and conferences within Sweden. The appropriateness of a qualitative approach with such sampling is in line with the conclusions of Nikula and Jantunen [8], who observe that "companies basing their business on OSS are likely to be better suited for qualitative methods".

The purposeful sampling led to 45 telephone interviews, conducted in Swedish (the native language of all interviewees and the interviewer) and transcribed. Of these, 5 interviews resulted in conversations with practitioners whose companies had no current involvement with OS. Any quotes from these 5 non-adopters are clearly noted in the text. All quotations used in the analysis phase and reported in the paper are translations into English.

The interviews were conducted over a two month period, and based on a number of open questions - a sub-set of which had one or more follow-up questions depending on the initial response. Specifically, questions for the analysis reported in this paper related to:

1. The concept of Open Source

2. Company use of OS products

3. Company participation in OS projects

\section{Results}

\subsection{Perceptions of $\mathrm{OS}$.}

Question: What is your immediate reaction when I say "Open Source"?

Firstly, it should be noted that the question deliberately probes immediate connections with the term, and that on several occasions this caused respondents to hesitate before replying. As put by one consultant: "is this a context where I must explain from the start what is meant by Open Source code, or can I take for granted that these people know what the term means? I ask myself whether I need to explain or not".

There is a great variation in perceptions of the OS phenomenon, which correlates reasonably well with the level of involvement with OS. In particular, we see four categories of involvement, the top level having two variants:

0: no OS

1: use of OS infrastructure internally

2: use of OS infrastructure and applications

3: involvement in code generation variant 1: commensalistic 
variant 2: symbiotic

The main discriminator of the category 3 companies is that OS is immediately associated with the business or process levels, or an ideological view. Respondents typically stressed one or other of these views, although some hesitated to give a short answer - in particular those heavily involved in OS projects ("that is a good question ..."; "I don't know, but ..."). However, their deep knowledge of the concept became evident during the course of the interview.

Those emphasising a process view associate the concept with, for example: "a development model", "collaboration and an ability to influence" or "that you develop the software together with the users". Some were more elaborate in their responses, for example "Freely available source code to tools or software where you try to use a large community over the whole world ... with Linux as the prime example" and "... Eclipse and such things ... a way of working in which you are contributing and use code in different ways."

Those taking a business view tend to associate the concept with their own business: "We build our entire business on it, so [the company] is my first thought."

The ideological view primarily stressed the OS community concept, placing it above the idea of OS products, for example "I think of community, and as a second thought of tools", in particular implying a "free-basis community" with "nonownership". Only one respondent in the study used the term "libre", which is common in the South of Europe.

A smaller group primarily associated OS with free access to the source code - a rather pragmatic view. Several respondents stressed the ability to modify source code: "literally that you get access to the source code and are allowed to modify the source code"; "I am allowed to play with it myself, if I want". This can be contrasted with the view from a non-OS user whose immediate association in this regard was rather different: "you are expected to modify [the code]".

The main discriminator of the category 0,1 and 2 companies was an emphasis on OS products, sometimes specific products, and properties of OS products - including quality and cost.

On the product side, the major association was with the LAMP suite - for example "My first thought is Linux". However, some were non-specific "application servers and testing tools, and similar things" and others went beyond LAMP in including desktop products also: "Linux, MySQL, Apache, OpenOffice etc.".

On the properties side, although many placed "no cost" uppermost in their minds, several referred to the quality of OS products: "I really think about very competent software" or even both: "software at no cost that often is just as good as commercial".

\subsection{Company use of OS products}

Question: Does your company use any Open Source products 
After this confirming question, the interviewer asked about the most important OS products for the company, and their general experience in using these products.

Overall, in citing the most important OS products for their company: $75 \%$ cited elements of the LAMP stack; $50 \%$ cited other infrastructure products; $12 \%$ cited Open Office; and 10\% cited OS tools for application development. Perhaps not surprisingly, with one exception all companies mentioning Open Office also mentioned Linux. In terms of quality, no negative comments were made about any OS product actually adopted. Some of the larger companies not heavily into OS development show higher scepticism, but more involved respondents did not share this scepticism. For example, "our experience is that [OS products] are very secure, and have become more stable over time; if you follow the distributions, you can see that it has improved over time".

The attitude of the respondents towards OS usage depended largely on the level of company involvement in OS. For example, a developer from a large company which ships products with OS components commented: "we have really tried to explore and asses the quality, so we typically don't read about them - instead we want to dig into the source code and assess the quality". Others differentiate between products which they ship, and those they use internally. For example, for one SME "as a consultancy company, we have adopted some OS products which we deploy at customer sites ... but Open Office is a product we use on a daily basis ourselves".

There is a perception that it takes longer to become productive using the LAMP stack, with developers able to more quickly use proprietary development tools "out of the box". However, the view of experienced LAMP developers is that this is not an ongoing problem.

An experienced OS developer, commenting on the quality of OSS, states that, in his view, it is "always good". Further, "functionality has increased significantly but above all the number of areas in which you can use OS". The Office package, for example, "wasn't available in a usable form five years ago but this is not at all a problem today." Another advantage seen with OS is that using OS products there is a better response to development questions. In the words of one developer: "Open Source is interesting because there is a potential for quickly developing code and quickly getting responses to questions in a way which you do not get in a commercial environment."

Alongside this, astute developers are aware of the broader costs of adopting software: "It is absolutely not for free, because you have to invest time in order to understand the software, and there is no possibility of writing formal complaints if it doesn't perform adequately. There is a certain risk associated with it". However, in his experience "the support in itself is easily as good as for commercial products".

Some company experience is with OS products not so commonly adopted amongst Swedish companies: "We use ObjectWeb, from a European OS consortium, which I would call a hidden pearl. We have used this in a large project at a customer site, and it runs on like a Swiss clock."

Finally, many companies are aware of the licensing advantages of OS: "What I like most with OS is the licence model. It gives a freedom and control over your IT investment, and that I think is a very important factor." 


\subsection{Company participation in OS projects}

\section{Question: Does your company participate in any Open Source projects}

After a positive response to this question, the interviewer clarified which ones and in what way the company was involved. Those not participating were asked whether there was a specific reason.

Of the companies actually using OSS within a development environment, $75 \%$ actively contribute to OS projects in one way or another. That is, $75 \%$ can be classified as having a symbiotic relationship with the OS community, the remaining $25 \%$ having a commensalistic relationship. Over $50 \%$ of all the companies in the survey were in one of these categories.

A number of companies proved to be highly active in the OS community. In the view of one developer: "life is too short not to get involved in OS development". Others are so heavily involved in OS within their business model, that they take it as a firm responsibility to be aware of, and actively encourage successful projects: "If you look on SourceForge there are 1,000,000 projects 950,000 of which consist of a piece of code which is going nowhere. There are a number which win in the longer term, and it is part of our job to identify those, and become active in them."

The level of activity varied widely. Some companies started OS projects by releasing source code under an OS licence. Others were strategically involved in OS projects as "commiters" and other leading roles, including responsibility for publicity. In other cases there was a lower level of interaction, including bug reports and submitting bug fixes for consideration.

\section{Discussion and Conclusions}

Open Source In this paper we have illuminated perceptions amongst stakeholders in Swedish companies adopting OS. These perceptions seem to graduate from OS perceived as specific tools and products to something which can revolutionise business models and development processes. One important factor seems to be the level of company commitment to OS, in that practitioners in companies contributing to OS projects or modifying OS code seem much more aware of the broader issues related to OS. Developer involvement with OS projects is apparent in half of the companies approached, and in the majority of these the relationship can be said to be symbiotic.

The observation about the very small percentage of OS projects which are likely to be successful may partly relate to the fact that most OS projects are developed by a tiny number of developers $[12,13]$. Within the projects adopted in Swedish companies, the vast majority are large, well known projects with significant diffusion. They can therefore be considered low risk. 
It is also worthy of note that large companies (over 250 employees) within the sample are more conservative in there uptake than SMEs, being primarily involved only at the level of adopting products from the LAMP suite. However there are exceptions, including both a large IT and a non-IT company, the latter with very specific requirements. Further, we found only one example of inner source development; that is, development of software within a company using Open Source processes and principles [14].

One question is why profit-oriented companies enter the OS field [15]. A number of Swedish companies now see a business in repackaging OS components and offering added value. Many adopt OS products and components within their own development activities, for competitive advantage. Some go further, releasing the products they have developed under OS licences. A strong motivation for both company and individual involvement in OS projects is seen as personal skills development. A major motivation for releasing code as OS is to gain benefit from a larger user and developer community. Of course, a prerequisite for obtaining such benefit is that the community can be built and sustained - something which has been shown to be complex [16].

Overall, the survey suggests that organisational involvement in OS development is a promoter of change: of perceptions, development processes and ultimately business models. This is a phenomenon worthy not only of monitoring but of studying, to understand the key tools, techniques, architectures, development methods and licensing for promoting symbiotic relationships. Such alignment is a challenge both for the OS communities and commercial software development organisations.

It is perhaps worth conjecturing how such alignment might be supported. OS champions within larger organisations might help this process by promoting inner source projects within their organisation. By doing this, the OS development model will be taken in-house, and organisational learning follow. OS communities could make it easier for organisations to assess the maturity and quality of products, thereby benefiting from wider uptake and increased interest and subsequent contributions. Responsiveness to contributions from commercial organisations is an issue which has been raised; it is sometimes difficult for organisations with substantive contributions to find an OS developer with upload rights who is willing to accept.

In conclusion, this study complements the findings of the FLOSS quantitative survey of Swedish companies, concentrating on qualitative issues in order to understand the underlying dynamics behind the OS phenomenon in companies adopting OS. In essence, though, some see the growth of OS usage in stark terms, as expressed by one interviewee: "Our company wouldn't be where it is today if not for Open Source". 


\section{Acknowledgements}

This research has been financially supported by the European Commission via FP6 Co-ordinated Action Project 004337 in priority IST-2002-2.3.2.3 'Calibre' (http://www.calibre.ie), and also by Sparbanksstiftelsen Alfa.

\section{References}

1. P. J. Ågerfalk, A. Deverell, B. Fitzgerald, and L. Morgan. Assessing the Role of Open Source Software in the European Secondary Software Sector: A Voice from Industry, In Proceedings of the 1st International Conference on Open Source Systems (Scotto, M. and Succi, G. Eds.), p. 82-87, Genoa, Italy (2005).

2. G. Lawton. LAMP Lights Enterprise Development Efforts, IEEE Computer, September, p. 18-20 (2005).

3. ITEA. ITEA Report on Open Source Software, ITEA: Information Technology for European Advancement. ITEA Office Association, January 2004, www.itea-office.org (2004).

4. P. Gustafson and W. Koff. Open Source for Business. Computer Science Corporation, California, <www.csc.com/features/2004/uploads/LEF_OPENSOURCE.pdfs, September, (2004).

5. M. Schütz, N. Khan, and A. Chand. A Baseline Survey on Free and Open Source Software (FOSS) in the South Pacific: Knowledge, Awareness, and Usage, ICT Capacity Building at USP Project, The University of South Pacific, ISBN 982-01-0640-0 (2005).

6. e-Cology. Open Source Software - OSS - In Canada: A Collaborative Fact Finding Study, e-Cology Corporation, <www.e-cology.ca/canfloss/report/CANfloss_Report.pdf $>$, September (2003).

7. J. Giera. The Costs And Risks Of Open Source, April 12, Forrester Research Inc., Cambridge, US (2004).

8. U. Nikula, and S. Jantunen. Quantifying the Interest in Open Source Systems: Case SouthEast Finland. In Proceedings of the 1st International Conference on Open Source Systems (Scotto, M. and Succi, G. Eds.), p. 192-95, Genoa, Italy (2005).

9. L. Dahlander and M. G. Magnusson. Relationships between open source software companies and communities: Observations from Nordic firms. Research Policy, 34(4), 481493 (2005).

10.S. Lussier. New Tricks: How Open Source Changed The Way My Team Works, IEEE Software, 21(1), 68-72 (2004). 
11.FLOSS. FLOSS Final Report - Part 1: Free/Libre Open Source Software: Survey and Study, University of Maastricht, The Netherlands www.infonomics.nl/FLOSS/report (2002).

12.S. Krishnamurthy. Cave or Community? An Empirical Examination of 100 Mature Open Source Projects, First Monday, 7(6), www.firstmonday.org/issues/issue7_6/ krishnamurthy/> (2002).

13.L. Zhao and S. Elbaum. Quality assurance under the open source development model. Journal of Systems and Software, 66(1), 65-75 (2003).

14.V. K. Gurbani, A. Garvert and J. D. Herbsleb. A Case Study of Open Source Tools and Practices in a Commercial Setting. In Proceedings of the 5th Workshop on Open Source Software Engineering, p. 24-29, ACM (2005).

15.C. Rossi and A. Bonaccorsi. Why profit-oriented companies enter the OS field? Intrinsic vs. extrinsic incentives, In Open Source Applications Spaces: Fifth Workshop on Open Source Software Engineering (5-WOOSE) May 17, ACM (2005).

16.J. West and S. O'Mahony. Contrasting Community Building in Sponsored and Community Founded Open Source Projects, In Proceedings of the 38th Annual Hawaii International Conference on System Sciences (HICSS'05) - Track 7, January 03-06, 2005, IEEE Computer Society, Los Alamitos, 10p (2005). 